\title{
The effect of wood particle size distribution on the mechanical properties of wood-plastic composite
}

\author{
Arif Delviawan ${ }^{1}$, Yoichi Kojima ${ }^{1 *} \mathbb{0}$, Hikaru Kobori ${ }^{1}$, Shigehiko Suzuki ${ }^{1}, K^{2}$ jeni Aoki ${ }^{1}$ and Shinji Ogoe ${ }^{2}$
}

\begin{abstract}
Commercial wood flour of pine (Pinus densiflora) was used as an experimental material. It was milled with different milling times $0,10,20,30,40,60$, and 120 min to investigate the effect of their particle size distribution on the mechanical properties of the wood-plastic composite. Two kinds of drying conditions, 7 days of freeze-drying at a temperature of $-45^{\circ} \mathrm{C}$ and heat drying $\left(80^{\circ} \mathrm{C}\right)$ for $24 \mathrm{~h}$ were applied. Polypropylene and maleic anhydride-grafted polypropylene were used as a matrix and the compatibilizer of the wood-plastic composite compound, respectively. Particle size analysis showed that an increase in the time of ball milling decreased the wood flour size. However, an excessive milling period of time longer than 40 min corresponded to an increase in the amount of aggregation. Scanning electron microscope images showed the existence of aggregation for the wood flour with 120 min of wet milling time. As the particle size decreased, mechanical properties of wood-plastic composite increased for up to 30 min of wet milling time and then slightly decreased. This behavior might be due to aggregation. The optimum mechanical property was obtained at 30 min of wet milling time under freeze-drying conditions.
\end{abstract}

Keywords: Freeze-drying, Heat drying, Mechanical properties, Particle size, Wood-plastic composite

\section{Introduction}

Wood-plastic composite (WPC) is a biocomposite product made from wood-based materials and polymers [1] by a variety of production techniques [2]. It is prepared under specific heat and pressure conditions [3]. WPC has advantages such as a lower maintenance requirement and better thermal properties, acoustic isolation, and durability than other wood-based materials [4]. One of the largest commercial applications for WPC is exterior use, such as outdoor decking applications [1]. Figure 1 shows an example of an outdoor decking application of WPC products. Other uses of WPC include automotive interior substrates, furniture, packaging, housing [5], and cladding applications [6].

\footnotetext{
*Correspondence: kojima.yoichi@shizuoka.ac.jp

${ }^{1}$ Faculty of Agriculture, Shizuoka University, 836 Ohya, Suruga-ku,

Shizuoka 422-8529, Japan

Full list of author information is available at the end of the article
}

The difficulty of waste decomposition can present a serious problem for the environment worldwide. Thus, significant efforts are needed to reduce the accumulation of waste and increase its use value. Using recycled materials and other fibers in the manufacturing of WPC could be a solution. Sawdust from wood processing industries, bagasse, rice hull (agro-waste), and recycled plastic can be used as raw materials for WPC. Besides improving the use value, using sawdust for the manufacturing of WPC could help minimize waste [3]. The advantages of agrowastes such as bagasse and rice straw are renewable, lowcost materials and easy availability [7]. The mechanical properties of WPC could be enhanced by adding a coupling agent $[8,9]$. This coupling agent would improve the interface compatibility between non-polar plastic and polar sawdust by providing a chemical interaction between both [10].

Wood flour (WF) is one of the most common natural fibers used in the thermoplastics industry and can be produced commercially from post-industrial sources, 


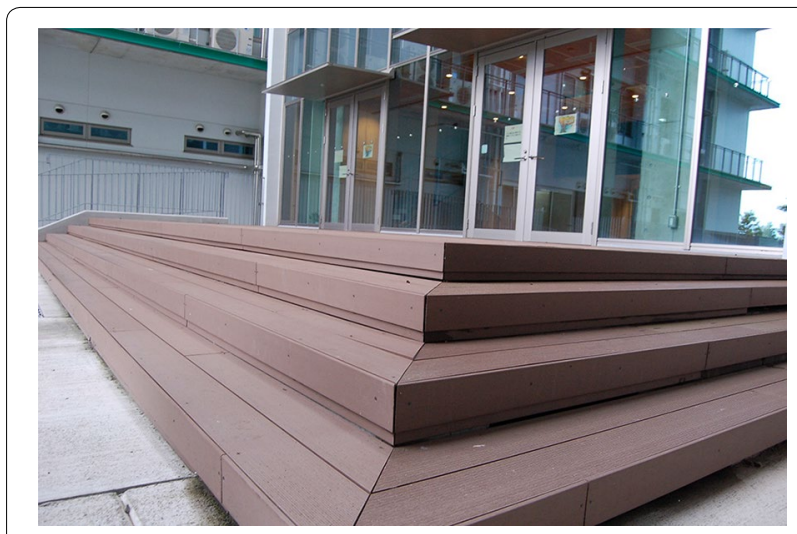

Fig. 1 An example of outdoor decking application of WPC products

such as planer shavings and sawdust [11]. Unused biomass resource such as forest thinning can be utilized as a filler of WPC [12]. However, for utilization of WF as a filler, several factors must be considered such as species and moisture content [13]. These parameters could be controlled by an appropriate selection of the raw material in the manufacturing of WPC. The quality of the wood fiber as raw materials depends on factors such as the chemical nature of the surface, distribution of the particles, content of impurities, and their shape and porosity. One of the important parameters that influences the strength of WPC is the size and configuration of WF [14].

The characteristics of WF as a raw material are important in the manufacturing of WPC. The quality and functionality of WPC should be improved to meet the increasing public demand. Reducing the particle size of WF to get a smaller, and more uniform of size can be accomplished with a ball mill machine. Besides particle size reduction, ball mills are also widely used for mixing, dispersing, and blending. Grinding in a ball mill is affected by the point contact of ore particles and balls, and for a given time, any degree of fineness can be achieved [15]. The wet ball milling process fibrillated the surface fibers of WF. The degree of fibrillation increased with increasing wet milling time [12]. Although various studies have been conducted, there are still unsolved factors such as the particle size distribution as a function of wet milling times and drying conditions. It is also necessary to consider the relationship between this factor and the properties of WPC. The objective of this study is to evaluate the relationship between the wood particle size distribution and the mechanical properties of WPC due to differences of wet milling times and drying conditions that was applied.

\section{Materials and methods}

\section{Materials}

Commercial WF of Japanese red pine (Pinus densiflora) was used as a filler. First, WF was screened to $\leq 2 \mathrm{~mm}$ by a rotor mill (FRITSCH, Pulverisette 14, Germany) at 20,000 rpm. Polypropylene (PP, J107G, Prime Polymer Co., Ltd., Japan) and maleic anhydride-grafted PP (MAPP, Kayabrid 006PP-N, Kayaku Akzo Co., Ltd., Japan) were used as a matrix and compatibilizer, respectively. PP was used in the form of a homopolymer powder, with a melt flow rate of $30 \mathrm{~g} / 10 \mathrm{~min}\left(230{ }^{\circ} \mathrm{C} / 2.16 \mathrm{~kg}\right)$ and $0.91 \mathrm{~g} / \mathrm{cm}^{3}$ of density. The MAPP powder had 2 wt\% MA content with an average molecular weight of $75 \mathrm{~kg} / \mathrm{mol}$. Injection and extrusion molding are two popular plastic molding methods in the industrial and manufacturing sector that are used to make products with varying shapes and sizes. Based on what is the useful of WPC product, they can be classified into: exterior use, interior use, and highperformance use. Exterior use usually made for decking, flooring, etc. In the case of this research, the WPC will be used for a special interior and high-performance product such as the part of bath, kitchen, some part of a machine, interior of the car, etc. Therefore, the kind of injection PP grade was used in this research.

\section{Methods \\ Filler fabrication}

The Japanese pine WF, $13.5 \mathrm{~g}$ was milled with $200 \mathrm{ml}$ of water by a ball mill (Pulverisette 5, Fritsch, Germany). This was the standard method of wet milling condition for "one pot" in this study. A rotating speed of $200 \mathrm{rpm}$ was applied, and the different wet milling times $(0,10$, $20,30,40,60$, and $120 \mathrm{~min}$ ) were tested. After wet milling, the two kinds of drying conditions were applied: 7 days of freeze-drying at a temperature of $-45{ }^{\circ} \mathrm{C}$ by a freeze dryer (FDU-1200, Eyela, Japan) and $24 \mathrm{~h}$ of heat drying by an oven dryer (SOFW-450S, Ettas, Japan) at a temperature of $80{ }^{\circ} \mathrm{C}$. Then, dried-WF was fibrillated for $1 \mathrm{~min}$ by a blender (IFM-800DG, Iwatani, Japan) and screened by mesh to be classified into six size bins as follows: > $425 \mu \mathrm{m}, 180-425 \mu \mathrm{m}, 90-180 \mu \mathrm{m}, 53-90 \mu \mathrm{m}$, $32-53 \mu \mathrm{m}$, and $<32 \mu \mathrm{m}$. A vibrational acceleration of \pm 20 $\mathrm{G}$ was applied for $30 \mathrm{~min}$ for each condition by a compact vibrating shaker (VSS-50D, Tsutsui, Japan).

To analyze the weight distribution at the WF size of 6 classifications and 7 milling times, the total weight of WF in each fraction of the $6 \times 7$ matrix conditions was calculated. The number of pots used in wet milling to obtain fibers is listed in Table 1 for heat drying and freeze-drying conditions. The number of pots for each condition was determined to obtain a sufficient amount for test piece fabrication and to analyze the particle size distribution. 
Table 1 The number of pots on WF fabrication

\begin{tabular}{lllllll}
\hline Conditions & \multicolumn{2}{l}{ Time (min) } & & & \\
\cline { 2 - 6 } & $\mathbf{0}$ & $\mathbf{1 0}$ & $\mathbf{2 0}$ & $\mathbf{3 0}$ & $\mathbf{4 0}$ & $\mathbf{1 2 0}$ \\
\hline Heat drying & 16 & 16 & 16 & 24 & 16 & 16 \\
Freeze-drying & 12 & 12 & 12 & 20 & 12 \\
\hline
\end{tabular}

This study focused on the fraction $90-180 \mu \mathrm{m}$ for the different wet milling times. The micro-structure of WF was investigated through a scanning electron microscope (JSM-6510LV, JEOL, Japan) examination. The particle size distribution of WF after milling, drying, and screening was analyzed by a laser diffraction particle analyzer (LA-950S2, Horiba, Japan). This laser diffraction particle analyzer was used to measure wet and dry samples in the range of $10 \mathrm{~nm}$ to $3000 \mu \mathrm{m}$. Wet sample method was applied in this research. Small amount of WF was put into sample bath to scatter the light at an angle determined by that particle size; larger particles scatter at small angles and smaller particles scatter at large angles. A collection of particles produced a pattern of scattered light defined by intensity and angle that was transformed into a particle size distribution.

\section{Manufacture of WPC}

The ratio of the weight of WF, PP, and MAPP in the compound was 25:74:1, respectively. This ratio of the weight was same as previous research and it was applied to avoid the interaction between WF itself [16]. The WPC compound (PP and MAPP) were mixed by a kneader under $190{ }^{\circ} \mathrm{C}$ with $30 \mathrm{rpm}$ for $3 \mathrm{~min}$. Then, WF was added to mix them for 10 min with an extruder machine (Laboplast Mill 30 R 150, Toyo Seiki Seisakusho Ltd., Japan). After kneading, the WPC compound was crushed by a crusher machine (Pulverizer SA-23, Stolz Co. Ltd., Japan). Melt kneading was carried out for $5 \mathrm{~min}$ at a temperature of $190{ }^{\circ} \mathrm{C}$ and a screw rotation speed of $50 \mathrm{rpm}$ by a twin-screw small kneader (Micro 5 cc Twin Screw Compounder, DSM Xplore, Netherlands). After that, the injection molding machine (Micro $5.5 \mathrm{cc}$ Injection Moulding Machine, DSM Xplore, Netherlands) was used to make WPC test specimens. The dimensions of a tensile test were $50 \mathrm{~mm}$ in length, $2 \mathrm{~mm}$ in thickness, $4 \mathrm{~mm}$ in width and those of the bending and impact test specimen was $50 \mathrm{~mm}$ in length, $2 \mathrm{~mm}$ in thickness, and $6 \mathrm{~mm}$ in width. The specimens were conditioned for 5 days or more in a constant temperature and humidity room $\left(20{ }^{\circ} \mathrm{C}, \mathrm{RH} 65 \%\right)$ before testing.

\section{Mechanical test}

The bending and tensile tests were conducted to evaluate the performance of WPC according to the JIS A 5741 standard [17]. The three-point bending flexural test was conducted using a universal testing machine (BT-805, Yasui Kikai, Japan). The speed of the test was $5 \mathrm{~mm} / \mathrm{min}$ and the span was $32 \mathrm{~mm}$. The number of replications for each condition was 5 . The flexural modulus $\left(E_{\mathrm{f}}\right)$ was calculated as follows:

$$
E_{\mathrm{f}}=\frac{\Delta F}{\Delta s} \times \frac{L^{3}}{4 b h^{3}} \times 10^{3},
$$

where $E_{\mathrm{f}}$ is flexural modulus (MPa), $L$ is the length of span $(\mathrm{mm}), h$ is the thickness of the test specimen $(\mathrm{mm})$, $b$ is the width of the test specimen (mm), $\Delta F$ is the difference between the upper limit load and lower limit load in the proportional range $(\mathrm{N})$, and $\Delta s$ is the difference between the upper limit deflection and lower limit deflection in the proportional range $(\mathrm{mm})$.

The tensile test was carried out by a universal testing machine (AGS-5kNX, Shimadzu Seisakusho, Japan). The speed of the test was $20 \mathrm{~mm} / \mathrm{min}$ and the distance between the gripper was $30 \mathrm{~mm}$. The number of replications for each condition was 5 . The tensile strength $\left(\sigma_{t}\right)$ was calculated using Eq. (2):

$$
\sigma_{t}=\frac{F_{t}}{A},
$$

where $\sigma_{\mathrm{t}}$ is the tensile strength (MPa), $F_{t}$ is the maximum load (N), and $A$ is the cross sectional at the beginning of the test specimen $\left(\mathrm{mm}^{2}\right)$.

An unnotched Izod impact test was conducted by the U-F Impact Tester machine (Ueshima Seisakusho, Japan) according to the JIS K 7110 standards [18]. The dimension of the test specimen was same as that of the bending test's specimen, and the number of replications was 5 for each condition. Izod impact strength $\left(a_{\mathrm{iN}}\right)$ was calculated using Eq. (3):

$$
a_{\mathrm{iN}}=\frac{W}{h b_{\mathrm{N}}} \times 10^{3}
$$

where $a_{\mathrm{iN}}$ is Izod impact strength $\left(\mathrm{kJ} / \mathrm{m}^{2}\right), h$ is the thickness of the test specimen $(\mathrm{mm}), b_{\mathrm{N}}$ is the width of the test specimen $(\mathrm{mm})$, and $W$ is the impact energy absorbed by the test specimen $(\mathrm{J})$.

A water resistance test, including two kinds of parameters water absorption and thickness swelling was 
conducted. The test specimen was put in the water and heated by oven (SOFW-450S, Ettas, Japan) at the temperature of $70{ }^{\circ} \mathrm{C}$. The dimensions of test specimen were measured at the $0,1,3,4,6$, and $12 \mathrm{~h}$. Then, measurements occurred once a day for the first week, followed by once every 3 days until saturation. Water absorption (WA) was calculated in Eq. (4):

$$
\mathrm{WA}(t)=\frac{W(t)-W_{0}}{W_{0}} \times 100,
$$

is the water absorption at time $t, W_{0}$ is the oven dried weight, and $W(t)$ is the weight of the specimen at a given immersion time $t$. The thickness swelling (TS) was calculated using Eq. (5):

$$
\mathrm{TS}(t)=\frac{T(t)-T_{0}}{T_{0}} \times 100,
$$

where $\operatorname{TS}(t)$ is the thickness swelling at time $t, T_{0}$ is the initial thickness of the specimens, and $T(t)$ is the thickness at time $t$.

\section{Results and discussion}

\section{Particle size distribution of WF}

The particle size distribution of WF after the ball milling process is shown in Fig. 2. Focused on large particle size around $800 \mu \mathrm{m}$, the highest intensity (peak) was observed for 0 min of wet milling time. Under that condition, the intensity was approximately $12 \%$, and it decreased with increase in wet milling time. The deviation of the particle

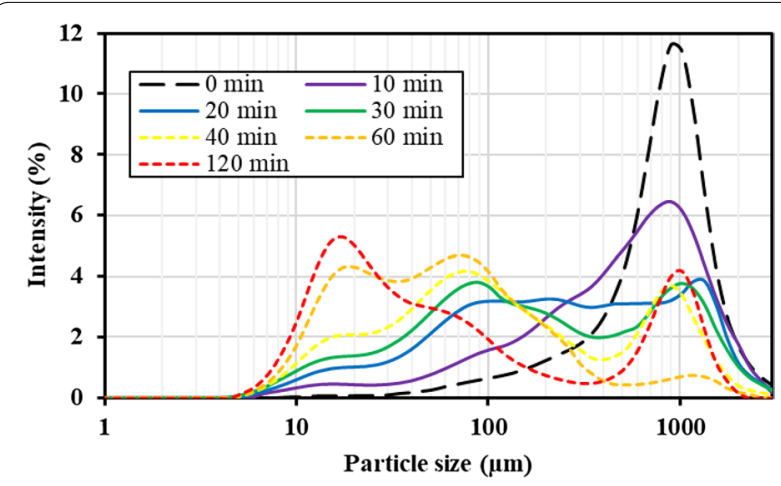

Fig. 2 The particle size distribution after pulverization by a ball mill size distribution demonstrated that there are various sizes and shapes in milled WF. The intensity increased from 1 to $4 \%$ at $60-120 \mathrm{~min}$ of wet milling time. The intensity near $100 \mu \mathrm{m}$ increased with increasing the wet milling time until 40 min of wet milling time. However, the intensity decreased from 5 to $2 \%$ at $60-120 \mathrm{~min}$ of wet milling time. At the smaller particle size (near $20 \mu \mathrm{m}$ ), the peak appeared at $120 \mathrm{~min}$ of wet milling time. This might be due to the milled WF into finer or fibers caused by the high rotating speed of the ball mill.

The percentage of dried-WF for $90-180 \mu \mathrm{m}$ of mesh pass obtained by heat drying and freeze-drying is shown in Table 2. Upon increasing the time of ball milling, the percentage of dried-WF increased up to $30 \mathrm{~min}$ of wet milling time. Thereafter, the percentage of dried-WF slightly decreased up to 60 min of wet milling time. However, a significant decline from 22 to $9 \%$ was found for heat drying at a milling time of $60-120 \mathrm{~min}$. The reason for this could be aggregation, which is discussed later. Conversely, at the same wet milling time, the percentage of dried-WF showed a significant increase for the freezedrying condition. Under this condition, the percentage increased from 25 to $35 \%$. It is suggested that freeze-drying prevented the aggregation of WF.

The particle distribution of dried-WF after the screening process for 90 to $180 \mu \mathrm{m}$ is shown in Fig. 3. Even after the screening process, there were particles with sizes of less than $90 \mu \mathrm{m}$ and more than $180 \mu \mathrm{m}$. This caused the particles to exhibit complex and irregular shapes, such that their particle size cannot be directly defined by this measurement. Therefore, there may be some particle sizes outside of the range of the relevant category. The WF obtained with heat drying condition can be seen in Fig. 3a and the dried-WF under the freeze-drying condition can be seen in Fig. 3b. Deviation of particle size distribution of the produced WF depends on the milling conditions. The standard deviation of freeze-drying condition showed higher than the standard deviation for heat drying, especially at the longer wet milling time. It was meant the particle size distribution of the freeze-drying condition was wider than that for the heat drying condition. Therefore, the highest intensity of particle size for the freeze-drying condition was lower than that for the heat drying. From 0 to $30 \mathrm{~min}$ of wet milling time, there was no peak for the larger particle size near $1000 \mu \mathrm{m}$.

Table 2 The percentage of produced WF for mesh pass $90-180 \mu \mathrm{m}$

\begin{tabular}{llllllr}
\hline Drying conditions & \multicolumn{6}{l}{ Wet milling time $(\mathbf{m i n})$} \\
\cline { 2 - 7 } & $\mathbf{0}$ & $\mathbf{1 0}$ & $\mathbf{2 0}$ & $\mathbf{3 0}$ & $\mathbf{4 0}$ & $\mathbf{6 0}$ \\
\hline Heat drying & 15.1 & 21.2 & 29.1 & 33.6 & 25.5 & $\mathbf{1 2 0}$ \\
Freeze-drying & 16.8 & 24.7 & 33.8 & 42.0 & 38.9 & 24.8 \\
\hline
\end{tabular}



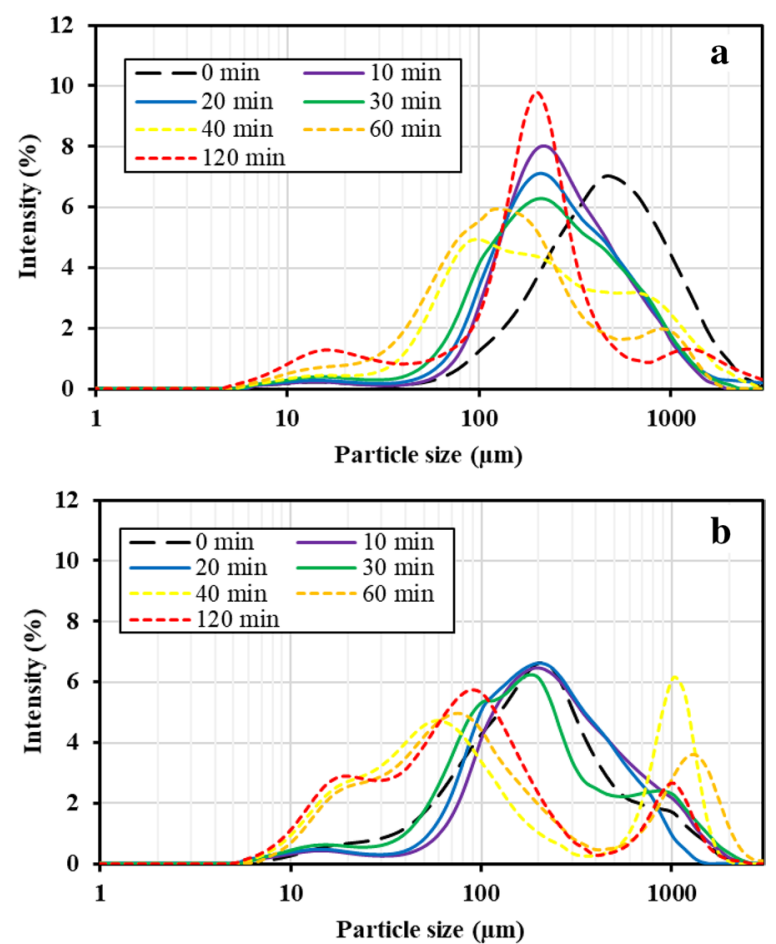

Fig. 3 The particle size distribution after the screened process for 90-180 $\mu \mathrm{m}$ obtained by $\mathbf{a}$ heat drying condition and $\mathbf{b}$ freeze-drying condition

However, for milling times of 40 up to $120 \mathrm{~min}$, the peak was shown to decrease with increase in the wet milling time. Under those conditions, the intensity for the freezedrying condition was higher than that for the heat drying condition. For the particle size near $100 \mu \mathrm{m}$, the intensity decreased as the wet milling time increased up to $30 \mathrm{~min}$. However, the intensity for a particle size near $100 \mu \mathrm{m}$ from 40 to 120 min increased with increase in the wet milling time. The highest intensity of milled WF for the heat drying condition was observed at a wet milling time of $120 \mathrm{~min}$, which might be due to aggregation. In the case of the smaller particle size near $20 \mu \mathrm{m}$, heat drying and freeze-drying conditions showed the same trend. As the wet milling time increased, the intensity near $20 \mu \mathrm{m}$ increased. Under this condition, the intensity for freezedrying was higher than that for the heat drying condition.

SEM images for WF at wet milling times 0,30 , and 120 min are shown in Fig. 4. As can be seen in Fig. 4a and $d$, there was an intact single particle for 0 min WF. At the wet milling time of $30 \mathrm{~min}$, there was a fibrillated particle under both heat drying and freeze-drying conditions, as shown in Fig. $4 \mathrm{~b}$ and e. However, at $120 \mathrm{~min}$ of wet milling time, it was found that the different surface characteristic of particle size between heat drying and freeze-drying. As can be seen in Fig. 4c, the surface of the heat drying WF was flat and low aspect ratio compared to $30 \mathrm{~min}$ (see Fig. 4b). This is due to the strong aggregation of milled small WF. This observation reinforces the drastic increase of the intensity around $200 \mu \mathrm{m}$ at wet milling time of $120 \mathrm{~min}$ in the particle size distribution in Fig. 3a. As can be seen in Fig. 4f, in the case of freezedrying at ball milling time of $120 \mathrm{~min}$, each particle size was smaller than heat drying and its surface was fibrillated. It is suggested that the $120 \mathrm{~min}$ of wet milling time produced the fibrillated particle and freeze-drying suppressed the aggregation of smaller particles compared to heat drying. The average particle size at a wet milling time of $120 \mathrm{~min}$ for the heat drying condition was higher than that for freeze-drying (see Fig. 5), demonstrating that aggregation occurred in this condition. However, WF became finer in the case of freeze-drying conditions.

The average particle size is calculated from the particle size distribution data by a laser diffraction particle analyzer machine. As shown in Fig. 5, the average particle size of WF for heat drying decreased at a wet milling time of $10 \mathrm{~min}$. At that time, the average particle size significantly decreased from 527 to $311 \mu \mathrm{m}$ and then increased to $333 \mu \mathrm{m}$ at $20 \mathrm{~min}$. However, the average particle size was decreased to $305 \mu \mathrm{m}$ at a wet milling time of $30 \mathrm{~min}$ and increased again to $329 \mu \mathrm{m}$ at a wet milling time of $40 \mathrm{~min}$. Finally, it increased drastically from 227 to $293 \mu \mathrm{m}$, from 60 to $120 \mathrm{~min}$ of wet milling time. There was an increase in the average particle size under freezedrying conditions from 266 to $320 \mu \mathrm{m}$ at a wet milling time of 0 to $10 \mathrm{~min}$, then decreased to $250 \mu \mathrm{m}$ at $20 \mathrm{~min}$. However, the average particle size increased again from 287 to $322 \mu \mathrm{m}$ from a wet milling time of 30 to $40 \mathrm{~min}$. Finally, it decreased rapidly from 331 to $194 \mu \mathrm{m}$ when the wet milling time was 60 up to $120 \mathrm{~min}$. There was no clear relationship between the average particle size and wet milling time. Therefore, another parameter, which could be used to explain the relationship between wet milling time and mechanical properties of the WPC was needed.

The correlation coefficient $(R)$ between the intensity at any particle size $(I p)$ and mechanical properties $(M)$ are calculated as the following Eq. (6):

$$
R_{M, I p}=\frac{\sum\left(M_{t}-\bar{M}\right)\left(I p_{t}-\overline{I p}\right)}{\sqrt{\sum\left(M_{t}-\bar{M}\right)^{2} \sum\left(I p_{t}-\overline{I p}\right)^{2}}},
$$

where $M_{t}, \bar{M}, I p_{t}$, and $\overline{I p}$ are any mechanical property at wet milling time $t$, mean mechanical property, intensity at $p \mu \mathrm{m}$ on the particle size distribution of wet milling time $t$ and its mean intensity, respectively. $R$ is calculated for the intensity at any particle size versus flexural modulus, tensile strength, and Izod impact strength. Because the particle size distribution pattern in freeze-dried and 

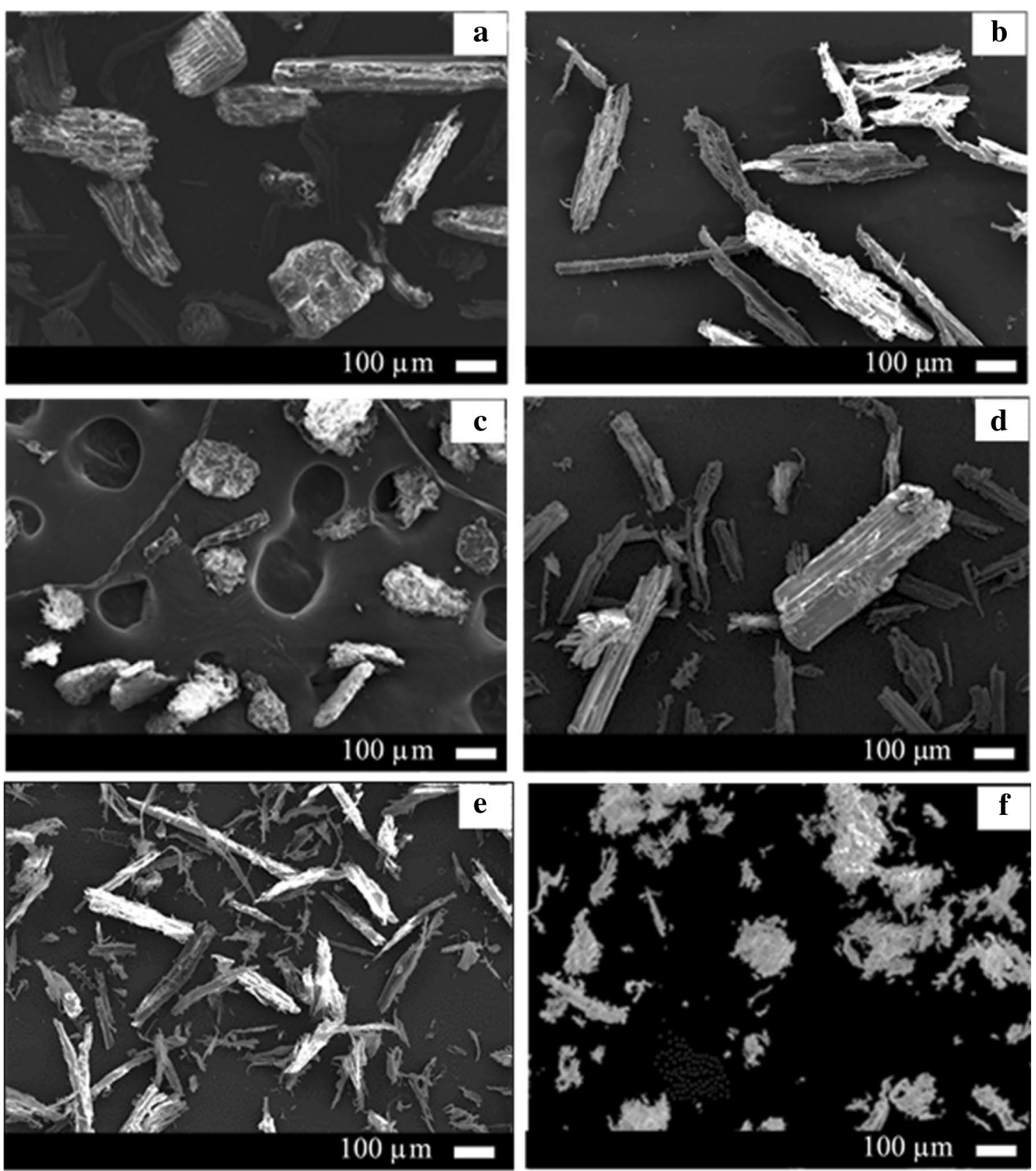

Fig. 4 The SEM image of WF. Heat drying condition: a 0 min, b 30 min and c 120 min of wet milling time. Freeze-drying condition: $\mathbf{d} 0$ min, e $30 \mathrm{~min}$ and $\mathbf{f} 120 \mathrm{~min}$ of wet milling time

heat-dried WF were different, $R$ for freeze-drying and heat drying were separately calculated. Note that $R$ is the parameter to evaluate only the 'linear' relationship between intensity and mechanical properties. The relationship between intensity and mechanical properties is not necessarily linear; therefore, $R$ is not a perfect parameter to determine the effective particle size that relates to the mechanical properties.

The correlation vector of the mechanical properties for each WF size was observed. The results showed that the mechanical properties at a particle size smaller than $100 \mu \mathrm{m}$ had negative correlation. Inversely, particle size from 100 to $900 \mu \mathrm{m}$ had positive correlation for 


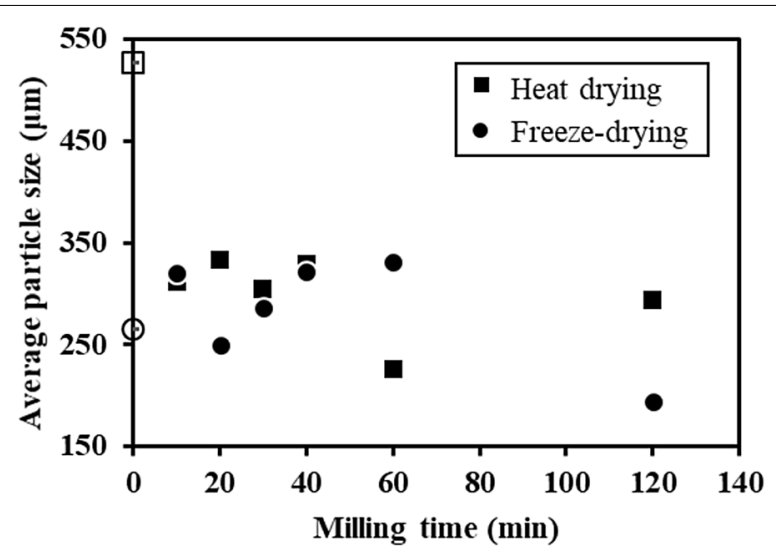

Fig. 5 The relationship between average particle size and milling time. Open square, heat drying 0 min and open circle, freeze-drying $0 \mathrm{~min}$

each mechanical properties of WPC. For heat-dried WF, correlation vector for mechanical properties at smaller particle less than $30 \mu \mathrm{m}$ had a negative correlation. However, particle size around $40-100 \mu \mathrm{m}$ and around $200 \mu \mathrm{m}$ showed positive and negative correlation, respectively. The highest correlation between mechanical properties was observed at a particle size $77.3 \mu \mathrm{m}$. Therefore, the intensity at $77.3 \mu \mathrm{m}$ was used as the parameter of smaller particle. On the other hand, the intensity at $678.5 \mu \mathrm{m}$, which also indicated a higher correlation between each mechanical property, was defined as the parameter of larger particle. Figure 6 shows the relationship between wet milling time and the intensity of small and large particles. As milling time increased, the intensity increased until $60 \mathrm{~min}$. In the case of heat drying, the intensity at wet milling time of $120 \mathrm{~min}$ drastically decreased. This results in the decrease of smaller particles due to aggregation during heat drying. In the case of freeze-drying, the intensity at $678.5 \mu \mathrm{m}$ linearly decreased until $60 \mathrm{~min}$ and then reached constant. This suggests that the large particle was successfully pulverized at $60 \mathrm{~min}$ of wet milling time. In the case of heat drying, the intensity did not decrease at less than $40 \mathrm{~min}$. The wet milling condition for both freeze and heat drying were identical; therefore, this might be due to the aggregation of small WF particles.

\section{Mechanical properties of WPC Flexural modulus of WPC}

Based on Table 3, the relationship between the mechanical properties of WPC and the intensity of small or large particles were investigated. Figure 7 shows the relationship between the flexural modulus and the intensity of small and large particles. As shown in Fig. 7a, an excessive percentage of small
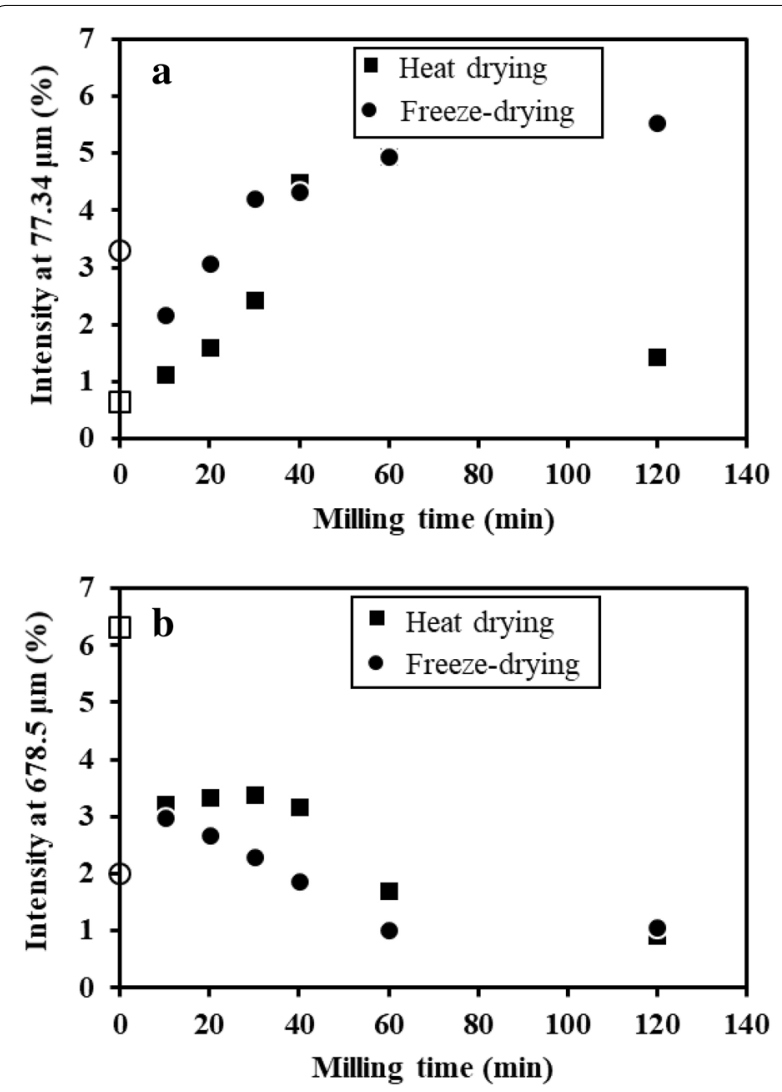

Fig. 6 The relationship between wet milling time and intensity of the particle size distribution analysis at $\mathbf{a} 77.3 \mu \mathrm{m}$ and $\mathbf{b} 678.5 \mu \mathrm{m}$. Open square, heat drying 0 min and open circle, freeze-drying 0 min

particles resulted in the decrease of flexural modulus. In the case of large particle, as shown in Fig. 7b the flexural modulus decreased during decreasing the intensity. The lowest flexural modulus was observed under the condition of heat drying with a wet milling time of $120 \mathrm{~min}$. As described above, the wet milling condition is the same for both freeze- and heat drying. Therefore, the actual amounts of smaller particles for the same milling time must be identical. It is suggested that the aggregation of smaller particles during heat drying reduces the apparent intensity for the small particles. The fact that the flexural modulus for small and large particle at $120 \mathrm{~min}$ of wet milling time showed a similar trend, that for freeze-drying is higher than that for heat drying. When the number of particles existing in WPC is considered, number of freezedried particles should be larger than that of heat-dried particles. By contrast, when we focused on the size of the particle, flexural modulus for heat drying condition should be higher than freeze-drying one since heat drying WF is larger than freeze-drying WF. However, heat drying sample showed slightly lower flexural 
Table 3 The mechanical properties of WPC for each condition

\begin{tabular}{|c|c|c|c|c|c|c|c|c|}
\hline \multirow[t]{2}{*}{ Drying condition } & \multirow{2}{*}{$\begin{array}{l}\text { Mechanical } \\
\text { properties }\end{array}$} & \multicolumn{7}{|c|}{ Wet milling time (min) } \\
\hline & & 0 & 10 & 20 & 30 & 40 & 60 & 120 \\
\hline \multirow[t]{3}{*}{ Heat drying } & $\begin{array}{l}\text { Flexural modulus } \\
(\mathrm{MPa})\end{array}$ & $3153.8(131.0)^{\mathrm{a}}$ & $3191.1(33.49)$ & $3605.9(243.4)$ & $3652.5(153.9)$ & $3486.8(40.42)$ & $3081.5(168.2)$ & $2337.8(16.46)$ \\
\hline & $\begin{array}{l}\text { Tensile strength } \\
(\mathrm{MPa})\end{array}$ & $44.3(0.68)^{\mathrm{a}}$ & $47.0(0.34)$ & $49.3(0.43)$ & $49.6(0.66)$ & $49.1(0.74)$ & $47.0(0.30)$ & $36.0(0.54)$ \\
\hline & $\begin{array}{l}\text { Izod impact } \\
\text { strength }\left(\mathrm{kJ} / \mathrm{m}^{2}\right)\end{array}$ & $8.7(0.60)^{a}$ & $8.9(0.52)$ & $8.3(0.79)$ & $9.1(0.93)$ & $10.0(1.84)$ & $9.9(0.87)$ & $6.2(1.20)$ \\
\hline \multirow[t]{3}{*}{ Freeze-drying } & $\begin{array}{l}\text { Flexural modulus } \\
(\mathrm{MPa})\end{array}$ & $3290.4(21.32)^{\mathrm{a}}$ & $3491.7(170.7)$ & $3513.1(147.9)$ & $3530.4(30.15)$ & $3289.2(88.82)$ & $2860.9(71.79)$ & $2552.3(68.92)$ \\
\hline & $\begin{array}{l}\text { Tensile strength } \\
\text { (Mpa) }\end{array}$ & $45.3(0.87)^{\mathrm{a}}$ & $49.3(1.12)$ & $50.1(0.56)$ & $50.6(0.48)$ & $49.0(0.27)$ & $47.0(0.50)$ & $42.7(0.22)$ \\
\hline & $\begin{array}{l}\text { Izod impact } \\
\text { strength }\left(\mathrm{kJ} / \mathrm{m}^{2}\right)\end{array}$ & $5.8(0.69)^{\mathrm{a}}$ & $6.1(0.32)$ & $8.1(0.88)$ & $8.1(1.42)$ & $9.3(2.16)$ & $8.1(1.19)$ & $13.8(1.44)$ \\
\hline
\end{tabular}

a Standard deviation
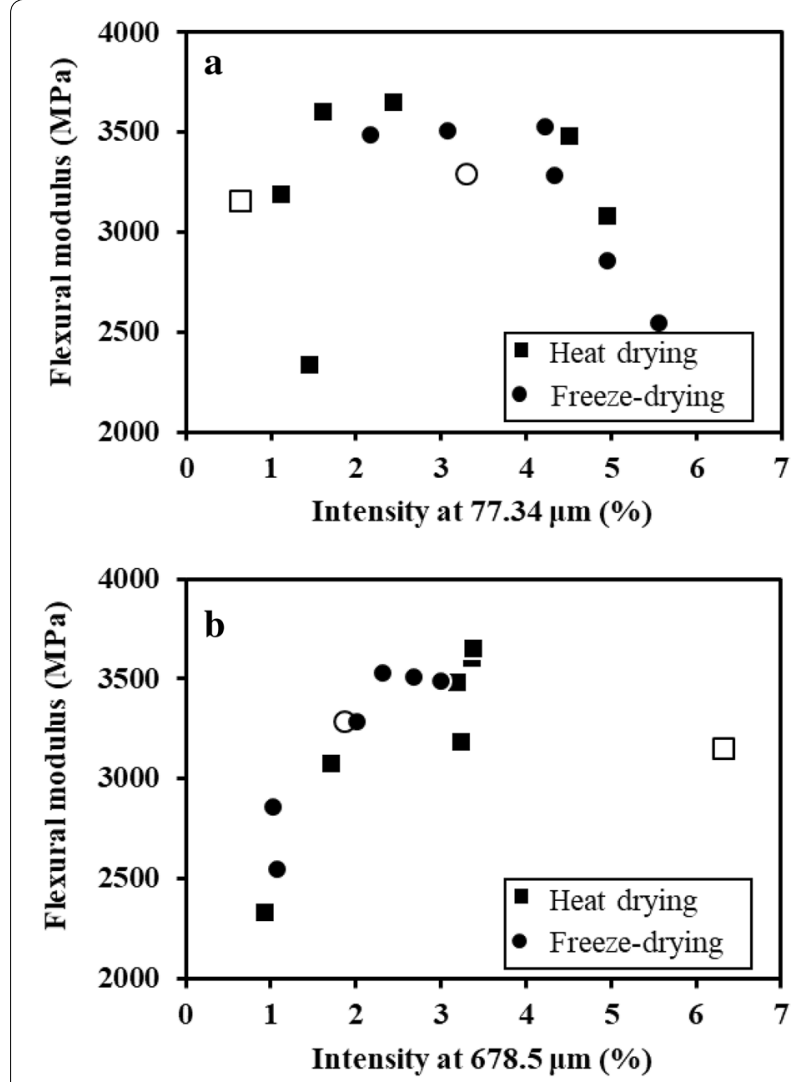

Fig. 7 The relationship between flexural modulus of WPC and intensity of the particle size distribution analysis at a $77.3 \mu \mathrm{m}$ and b $678.5 \mu \mathrm{m}$. Open square, heat drying $0 \mathrm{~min}$ and open circle, freeze-drying 0 min

modulus than freeze-drying sample. It is suggested that in the case of increasing this aggregated WF, the flexural modulus decreased. These results suggest that the aggregated particle may reduce the reinforcement efficiency between the entanglement of PP side.

Table 3 shows the mechanical properties of WPC with different milling time and drying conditions. In this study, the flexural modulus of WPC is shown to increase from 0 to $30 \mathrm{~min}$ of wet milling time. The highest flexural modulus of WPC was found at a milling time of $30 \mathrm{~min}$. Under that condition, there was no significant difference between heat drying and freeze-drying. Then, from 40 to 120 min of wet milling time the flexural modulus of WPC decreased. Referring to the SEM image in Fig. 4, it was suggested that the aggregation of WF occurred at a wet milling time longer than $30 \mathrm{~min}$. In the case of $120 \mathrm{~min}$ of wet milling time, the flexural modulus of WPC decreased. At that time, the flexural modulus of WPC for freeze-drying was higher than that for heat drying conditions, probably due to the difference in aggregation.

\section{The tensile strength of WPC}

According to Table 3, the tensile strength of WPC increased from 0 to $30 \mathrm{~min}$ of wet milling time. The highest tensile strength of WPC was found at $30 \mathrm{~min}$. Then, at over $40 \mathrm{~min}$ of wet milling time, the tensile strength of WPC decreased. The SEM image in Fig. 4 shows that the aggregation of WF occurred at over $40 \mathrm{~min}$ of wet milling time. The relationship between tensile strength and intensity on small and large particle is shown in Fig. 8. In the case of $77.3 \mu \mathrm{m}$, higher tensile strength was exhibited when the intensity was around $2-4 \%$ (see Fig. 8a). Neither an over-nor an under-percentage of intensity decreased the tensile strength. It is suggested that there is an appropriate amount of small particle that would yield the desired tensile strength of WPC. The flexural modulus for 120 min of wet milling with heat drying showed notably lower values than that for freeze-drying, 

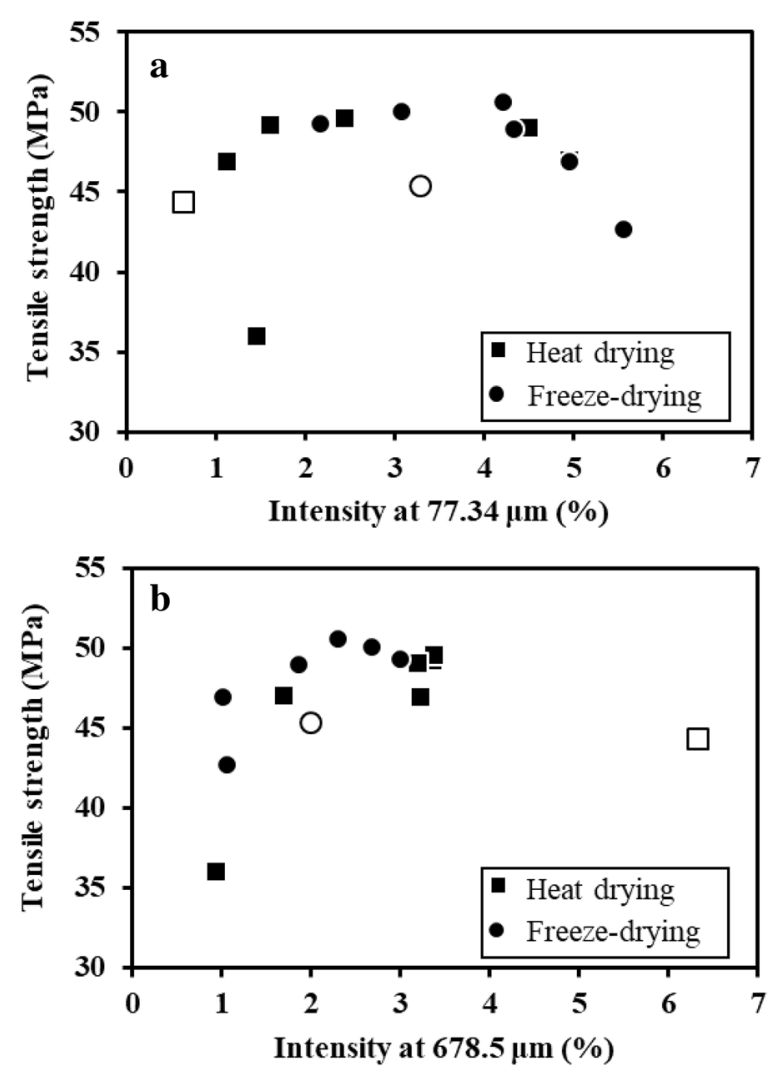

Fig. 8 The relationship between tensile strength of WPC and intensity of the particle size distribution analysis at a $77.3 \mu \mathrm{m}$ and $\mathbf{b} 678.5 \mu \mathrm{m}$. Open square, heat drying $0 \mathrm{~min}$ and open circle, freeze-drying 0 min

indicating the aggregation of smaller particle influencing the tensile strength of WPC. Contrarily, no relation between the intensity at $678.5 \mu \mathrm{m}$ and tensile strength was observed (see Fig. 8b).

\section{Izod impact strength of WPC}

Figure 9 shows the relationship between the impact strength and intensity at $77.3 \mu \mathrm{m}$ and $678.5 \mu \mathrm{m}$. In the case of heat drying, except at $120 \mathrm{~min}$, the impact strength gradually increased with increasing intensity at $77.3 \mu \mathrm{m}$. In the case of freeze-drying, increasing intensity increased the impact strength. However, there was no clear relationship between intensity at $678.5 \mu \mathrm{m}$ and impact strength. The amount of large particle might not affect the impact strength. When focused on Izod impact strength (see Table 3), there is no clear relationship between the Izod impact strength and wet milling time. In the case of the wet milling time at 120 min, the impact strength was higher and has a different trend compared to the others. It is found that the freeze-drying condition was higher than the heat drying condition, which might be due to the difference in aggregation.
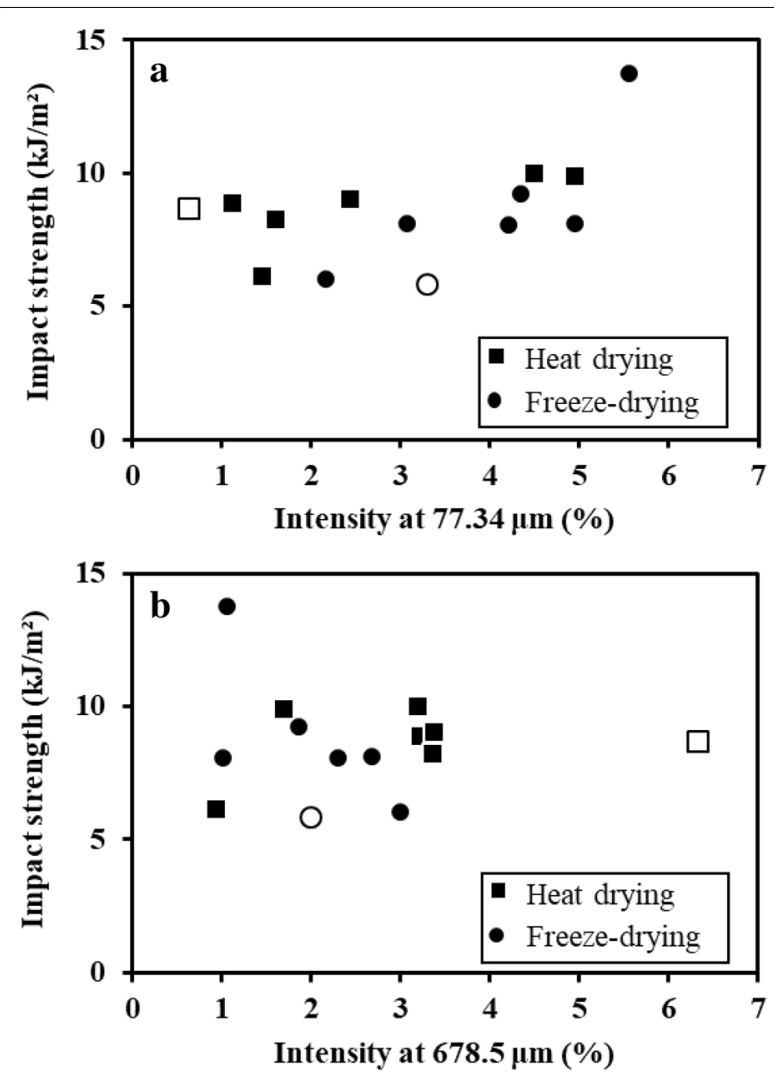

Fig. 9 The relationship between impact strength of WPC and intensity of the particle size distribution analysis at a $77.3 \mu \mathrm{m}$ and $\mathbf{b} 678.5 \mu \mathrm{m}$. Open square, heat drying $0 \mathrm{~min}$ and open circle, freeze-drying 0 min

\section{Water resistances of WPC}

Figure 10 shows the relationship between the intensity at $77.3 \mu \mathrm{m}$ and 678.5 on the particle size distribution and the WA and thickness swelling of the WPC. When focused on the saturated condition, water resistance properties showed the same trend, even for the large and small particle of WF. As observed in Fig. 10a and c, there is no significant difference on water absorption at the large and small particle for the heat drying and freeze-drying condition. In the case of thickness swelling showed that there is fluctuation among different wet milling times (see Fig. 10b and d). The reason might be to the differences of aggregation. Increase in the aggregation particle corresponds to a decrease in the dimensional stability against water.

The different structures of the particle may also contribute to different degrees of water uptake, especially in dimensional swelling, such as thickness of the composites. The possibility water to absorb is same because the amount of water itself is same. In the case of thickness swelling, specifically on the aggregated WF, even the water amount is same. However, the size of dimension 

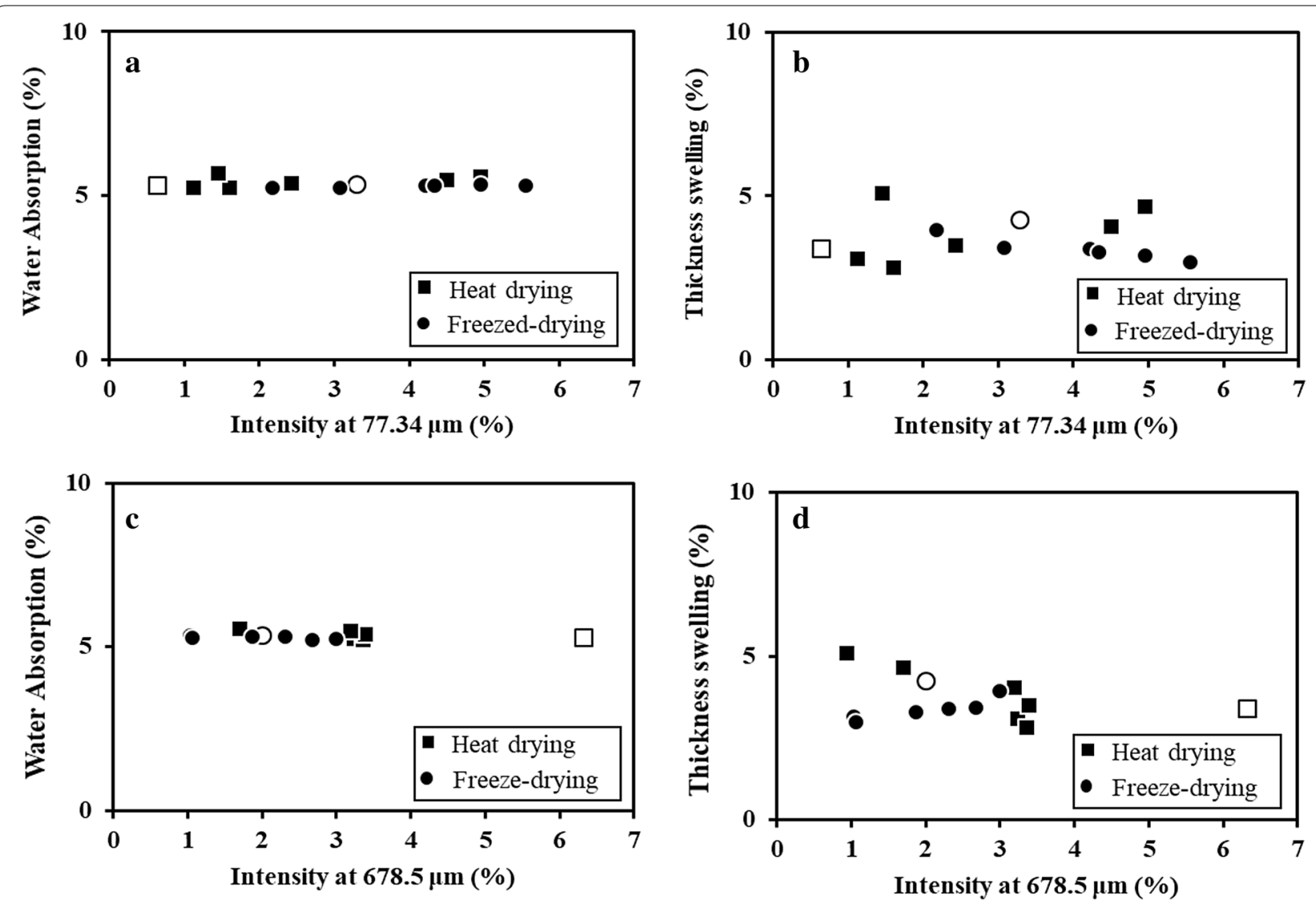

Fig. 10 The relationship between water resistance properties of WPC and the intensity of the particle size distribution: $\mathbf{a}$ intensity at $77.3 \mu \mathrm{m}$ versus water absorption, $\mathbf{b}$ intensity at $77.3 \mu \mathrm{m}$ versus thickness swelling, $\mathbf{c}$ intensity at $678.5 \mu \mathrm{m}$ versus water absorption, and $\mathbf{d}$ intensity at $678.5 \mu \mathrm{m}$ versus thickness swelling. Open square, heat drying 0 min and open circle, freeze-drying 0 min

will expand higher compared to the singular particle of WF. During the absorption, first, the water uptake occurred on the surface of the particles; then, the water transferred from one cell lumen to another over time [19]. The primary and secondary kneading also might influence the speed of water absorption. Under a temperature of $190{ }^{\circ} \mathrm{C}$, the thermoplastic polymer PP was able to cover the surface of WF and would provide greater strength to the WPC. In the case of this kneading process, the particles of thermoplastic polymer PP might be unable to cover such a large number of surfaces of wood particles. This would affect the WA of WPC as a result of the water absorption by the wood.

\section{Conclusion}

In this study, the effect of particle size distribution on the mechanical properties of WPC was investigated. The milling process changed the characteristic of WF, particularly the particle size distribution. An excessive milling period of time longer than 40 min increased the amount of aggregation. From the observation of particle size distribution, it was clearly found that the average particle size after ball milling increased as a function of milling time, particularly from 60 to $120 \mathrm{~min}$.

The result indicates that the tensile strength and flexural modulus of WPC increased up to $30 \mathrm{~min}$ of wet milling time. At 120 min of wet milling time, the mechanical properties decreased and that for freeze-drying was higher than that for heat drying. It was suggested that the different surface characteristics of aggregated WF influence the mechanical properties of WPC. Decreasing the particle size corresponded to an increase in the mechanical properties of WPC. The Izod impact strength increased with increasing wet milling time from 0 to $30 \mathrm{~min}$ and then showed a slight decrease. In the case of $120 \mathrm{~min}$ of wet milling time, the composite had a higher impact strength compared to other conditions. The reason for these might be due to the aggregation.

The result showed that the particle size distribution influences the mechanical properties of WPC. An excessive percentage of small particles decreased the mechanical properties of WPC. In the case of large particles, 
the mechanical properties of WPC decreased during decrease in intensity. The optimum mechanical property of WPC was obtained at $30 \mathrm{~min}$ of the wet milling time for freeze-drying conditions.

\author{
Abbreviations \\ WPC: wood-plastic composite; WF: wood flour; PP: polypropylene; MAPP: \\ maleic anhydride-grafted polypropylene.
}

\section{Acknowledgements}

The authors are grateful to the members of TOCLAS Co. Ltd., Mr. Masaki Okamoto, Mr. Tomoyuki Ema, and Ms. Keiko Kagawa for their cooperation, opportunities to collaborate, and the support such that this research could be completed.

\section{Authors' contributions}

$A D, H K$, and $Y K$ have participated sufficiently in this work to take public responsibility for the entire of the manuscript's content. SS, KA, and SO have participated sufficiently in this work to take public responsibility for a part of the manuscript's content. All authors read and approved the final manuscript.

\section{Funding}

Nothing.

\section{Availability of data and materials}

Not applicable.

\section{Competing interests}

The authors declare that they have no competing interests.

\section{Author details}

${ }^{1}$ Faculty of Agriculture, Shizuoka University, 836 Ohya, Suruga-ku, Shizuoka 422-8529, Japan. ${ }^{2}$ Toclas Corporation, 1370, Nishiyama-cho, Nishi-ku, Hamamatsu 423-8001, Japan.

Received: 25 June 2019 Accepted: 11 December 2019

Published online: 23 December 2019

\section{References}

1. Gardner DJ, Han Y, Wang L (2015) Wood-plastic composite technology. Springer Int Pub 1(3):139-150

2. Najafi A, Eslam HK (2011) Lignocellulosic filler/recycled HDPE composites: effect of filler type on physical and flexural properties. BioResources 6(3):2411-2424

3. Rahman KS, Islam MN, Rahman MM, Hannan MO, Dungani R, Khalil HPSA (2013) Flat-pressed wood plastic composites from sawdust and recycled polyethylene terephthalate (PET): physical and mechanical properties. SpringerPlus 2(629):1-7

4. García M, Hidalgo J, Garmendia I, Jaca JG (2009) Wood-plastics composites with better fire retardancy and durability performance. Compos A 40:1772-1776
5. English BW, Falk RH (1995) Factors that affect the application of woodfiber-plastic composites. In: Proc of wood fiber-plastic composites: virgin and recycled wood fiber and polymers for composites, May 1-3, 1995, Madison, WI, pp 189-194

6. Friedrich D, Luible A (2016) Investigations on ageing of wood-plastic composites for outdoor applications: a meta-analysis using empiric data derived from diverse weathering trials. Constr Build Mater 124:1142-1152

7. Naguib HM, Kandi UF, Hashem Al, Baghdady Y (2015) Effect of fiber loading on the mechanical and physical properties of "green" bagassepolyester composite. J Radiat Res Appl Sci 8(4):544-548

8. Isa A, Minamino J, Mizuno H, Suzuki S, Kojima Y, Ito H, Makise R, Okamoto M, Hasegawa T (2013) Increased water resistance of bamboo flour/polyethylene composites. J Wood Chem Technol 33:208-216

9. Martins G, Antunes F, Mateus A, Malça C (2017) Optimization of a wood plastic composite for architectural applications. Procedia Manufacturing 12:203-220. https://doi.org/10.1016/j.promfg.2017.08.025

10. Animpong MAB, Oduro WO, Koranteng J, Benefo KA, Mensah GB, Kumi KA, Tottimeh GO, Amoah JY (2017) Coupling effect of waste automotive engine oil in the preparation of wood reinforced LDPE plastic composites for panels. S Afr J Chem Eng 24:55-61

11. Stark NM, Rowlands RE (2003) Effects of wood fiber characteristics on mechanical properties of wood/polypropylene composites. Wood Fiber Sci 35(2):167-174

12. Isa A, Toyoda T, Suzuki S, Kojima Y, Ito H, Makise R, Okamoto M (2014) The effects of wet-milled wood flour on the mechanical properties of wood flour/polypropylene composites. J Wood Chem Technol 34:20-30

13. Stark NM, Berger MJ (1997) Effect of species and particle size on properties of wood-flour-filled polypropylene composites. In: Proceedings of functional fillers for thermoplastic and thermosets, INTERTECH/USA, Conference, California, 8-10 Dec 1997

14. Nourbakhsh A, Karegarfard A, Ashori A, Nourbakhsh A (2010) Effects of particle size and coupling agent concentration on mechanical properties of particulate-filled. J Thermoplast Compos Mater 23:169-174. https:// doi.org/10.1177/0892705709340962

15. Wills BA, Napier-Munn TJ (eds) (2006) Wills' mineral processing technology: an introduction to the practical aspects of ore treatment and mineral recovery, 7th edn. Butterworth-Heinemann, Oxford

16. Murayama K, Ueno T, Kobori H, Kojima Y, Suzuki S, Aoki K, Ito H, Ogoe S, Okamoto M (2019) Mechanical properties of wood/plastic composites formed using wood flour produced by wet ball-milling under various milling time and drying methods. J Wood Sci 69:5. https://doi. org/10.1186/s10086-019-1788-2

17. JIS A 5741: 2016 (2017) Wood-plastic recycled composite (in Japanese). Japanese Standards Association, Tokyo, pp 1-21

18. JIS K 7110: 1999 (2012) Plastics determination of Izod impact strength (in Japanese). Japanese Standards Association, Tokyo, pp 1-30

19. Mu B, Wang H, Hao X, Wang Q (2018) Morphology, mechanical properties and dimensional stability of biomass particles/high density polyethylene composites: effect of species and composition. Polymers 10:308. https:// doi.org/10.3390/polym10030308

\section{Publisher's Note}

Springer Nature remains neutral with regard to jurisdictional claims in published maps and institutional affiliations. 